\author{
A New Look at the Returns and Risks to Pharmaceutical R\&D \\ Author(s): Henry Grabowski and John Vernon \\ Source: Management Science, Vol. 36, No. 7 (Jul., 1990), pp. 804-821 \\ Published by: INFORMS \\ Stable URL: http://www.jstor.org/stable/2632320 \\ Accessed: 13/08/2009 20:13
}

Your use of the JSTOR archive indicates your acceptance of JSTOR's Terms and Conditions of Use, available at http://www.jstor.org/page/info/about/policies/terms.jsp. JSTOR's Terms and Conditions of Use provides, in part, that unless you have obtained prior permission, you may not download an entire issue of a journal or multiple copies of articles, and you may use content in the JSTOR archive only for your personal, non-commercial use.

Please contact the publisher regarding any further use of this work. Publisher contact information may be obtained at http://www.jstor.org/action/showPublisher?publisherCode=informs.

Each copy of any part of a JSTOR transmission must contain the same copyright notice that appears on the screen or printed page of such transmission.

JSTOR is a not-for-profit organization founded in 1995 to build trusted digital archives for scholarship. We work with the scholarly community to preserve their work and the materials they rely upon, and to build a common research platform that promotes the discovery and use of these resources. For more information about JSTOR, please contact support@jstor.org. 


\title{
A NEW LOOK AT THE RETURNS AND RISKS TO PHARMACEUTICAL R\&D*
}

\author{
HENRY GRABOWSKI AND JOHN VERNON \\ Department of Economics, Duke University, Durham, North Carolina 27706
}

\begin{abstract}
This study investigates the returns to R\&D for 100 new drugs introduced into the United States during the decade of the 1970s. In contrast to prior studies, it incorporates several significant structural changes that have occurred in the pharmaceutical industry during the $1980 \mathrm{~s}$. These include higher real drug prices and a greater degree of generic competition. A major finding is that the return on $R \& D$ for the average new drug is approximately equal to the 9 percent industry cost of capital. However, the performance of new drugs introduced during the latter half of the 1970s was markedly better than that of early 1970 s introductions. This latter finding is consistent with the more rapid rate of industry growth in real R\&D expenditures. The study also finds that the variation in returns is highly skewed, with only the top 30 drugs covering mean $R \& D$ costs on a fully allocated basis. Finally, it is shown that real drug price increases in the 1980 s were necessary for the average new drug introduction to recover its R\&D costs.

(PHARMACEUTICALS; DRUGS; R\&D; RETURNS; RISK)
\end{abstract}

A number of past studies have been performed on the returns to pharmaceutical R\&D activity. These studies indicate that the rate of return to pharmaceutical R\&D fell significantly during the 1960s and early 1970s. They find a mean real return of between 4 to 6 percent for post-1962 new drug introductions. Overall, existing studies present a picture of declining and low real returns to pharmaceutical $R \& D$ over the past few decades.

Lower returns on new drug introductions during the 1960s and 1970s can be traced to various factors, including more stringent health and safety regulations (Grabowski and Vernon 1983). Nevertheless, one would expect the industry to adapt to an unfavorable regulatory environment through changes in research strategy, product prices, firm attrition and other means. ${ }^{1}$ Although the adjustment process may take several years, returns on R\&D should eventually come back in line with the industry's cost of capital.

Investment behavior in pharmaceuticals suggests a more favorable environment for R\&D activity has emerged in recent years. While $R \& D$ investment in drugs slowed markedly during the 1970 s, it has been growing at a rapid rate during the 1980s. In particular, U.S. pharmaceutical industry $R \& D$ expenditures have been growing at an annual rate in excess of ten percent over the current decade (Grabowski 1989).

A new look at the returns to pharmaceutical R\&D therefore would appear timely. Existing rate of return studies predate several developments that are relevant to assessing the returns to pharmaceutical R\&D. First, beginning in the latter half of the 1970s, the industry experienced the introduction of several important new drug products from a therapeutic standpoint. Second, there has been a major change in drug pricing patterns during the $1980 \mathrm{~s}$. Third, product life cycles have changed during the $1980 \mathrm{~s}$, particularly in the post-patent period where generic competition is now more intense than in the past. Fourth, the trends in foreign market sales experienced by U.S. new drug introductions have also changed significantly in the current decade.

In the present analysis, we consider the economic performance of new drugs introduced during the 1970s. We are interested in seeing whether these new product introductions

* Accepted by Alok K. Chakrabarti; received April 4, 1989. This paper has been with the authors 1 month for 1 revision.

${ }^{1}$ With regard to the issue of firm attrition, a number of studies have shown that increased regulation had a particularly adverse effect on smaller sized firms. This group of firms now account for a much smaller fraction of industry R\&D than in the pre-1962 period (Grabowski and Vernon 1976) (Thomas 1988). 
have obtained higher returns than in earlier periods. In addition, it is instructive to examine how returns are affected by the drug pricing patterns which emerged in the 1980s. Real price increases in pharmaceuticals have received increasing attention by policymakers, including recent congressional hearings (U.S. Congress 1985, 1987). Another important objective is to analyze the effects of several policy developments, such as evolving cost containment programs. Insights into the potential impact of these changes on $R \& D$ returns can be obtained from a sensitivity analysis of our main results.

The next section of the paper discusses prior studies and recent trends in the pharmaceutical industry in more detail. The following one covers the major assumptions and basic methodology of the analysis. The final two sections present the main findings and the results of various sensitivity analyses.

\section{Prior Studies and Recent Trends}

Most studies of the returns to pharmaceutical $\mathrm{R}$ and $\mathrm{D}$ have found low yields in the post-1962 Drug Amendment period. On the basis of an econometric analysis, Baily (1972) estimated nominal pre-tax returns to pharmaceutical R\&D dropped from over 30 percent pre-1962 to less than 15 percent post-1962. Using a somewhat different methodological approach, Statman (1983) found nominal after tax returns on pharmaceutical $\mathrm{R}$ and $\mathrm{D}$ declined from 20 percent in the mid 1950s to about 10 percent in the late 1970s. Schwartzman (1975) estimated real after tax returns were between 3.3 to 7.5 percent for the 1966 to 1972 period. Joglekar and Patterson (1986) have performed the most recent and comprehensive study on this subject. Their best estimate of the real after tax returns on pharmaceutical R\&D was approximately 6 percent for a new drug compound beginning $\mathrm{R} \& \mathrm{D}$ in the mid $1970 \mathrm{~s}$.

A major limitation of all the current studies is that they employ data and extrapolate drug industry trends from the 1960s and 1970s. None employ any data from the 1980s. ${ }^{2}$ However the investment and product life cycles for new pharmaceuticals span several decades of time. Moreover, the industry has experienced important changes in recent years that have potentially significant implications for the returns to R\&D.

First, there appears to be a distinct improvement in research opportunities within the last decade. ${ }^{3}$ There has been an explosive growth in basic biomedical knowledge and research. Consistent with this situation, pharmaceutical $R \& D$ is increasingly characterized by a "discovery by design" approach. This in contrast to the random screening approach which was more prevalent in the earlier post World War II period (Grabowski and Vernon 1983, Chapter 2). In addition, research is now increasingly directed to chronic rather than acute health care problems. Drug therapies for chronic use have accounted for an increasing share of the major new drug introductions of recent periods.

There have also been important changes in the life cycle pattern of expected revenues for new product introductions during the 1980s. There is some evidence that product lifetimes are becoming shorter. A more rapid introduction of close substitutes to the pioneer drug compound in various therapeutic groupings is taking place. ${ }^{4}$ This apparently

\footnotetext{
${ }^{2}$ The most recent study by Joglekar and Patterson (1986) examines 218 new chemical entities introduced between 1962 and 1977. The latest year for which sales data were utilized was 1981 in this study. Their sensitivity analysis considers some of the emerging trends in the 1980s, such as increased generic competition and changing drug price behavior.

${ }^{3}$ This is also suggested by a recent analysis of the new products achieving 100 million dollars of U.S. sales by the fifth year of market life. There were 11 such products introduced between 1977 and 1982 as opposed to only 3 such products introduced between 1970 and 1976 (Grabowski 1989).

${ }^{4} \mathrm{~A}$ good example of this phenomenon is the case of Tagamet, the leading product introduction in terms of U.S. sales in the 1970s. Since its introduction in 1978, there have been three anti-ulcer product substitutes introduced and one of these products, Zantac, now has a larger share of the market. A regression analysis that we performed on the sales of new product introductions in our sample indicates that peak sales are generally occurring sooner after the date of introduction than was the case for older products.
} 
reflects several factors. These include increased diversification of R\&D programs by major firms and the ability of firms to use the discovery by design approach to produce closely substitutive as well as pioneer products.

The most significant change in product life cycles, however, is the much greater generic competition experienced in the post-patent period. Traditionally in pharmaceuticals, when the patent of a pioneering brand expired, the loss of sales to less expensive generic products occurred only very gradually (Statman 1981). However, this situation has changed dramatically in the 1980's. The repeal of state anti-substitution laws and the passage of the 1984 Drug Price Competition and Patent Restoration Act have been important factors in this regard. ${ }^{5}$ In preliminary research covering 18 drug compounds in which a patented brand name product was first subjected to generic competition in the 1983-1987 period, we have found that generics achieved an average unit market share of 49 percent by two years after market entry (Grabowski and Vernon 1989).

There has also been an important change in industry pricing behavior. During the 1970s, U.S. drug prices lagged overall economy wide inflation. At the end of the 1970s, however, drug firms began increasing product prices significantly faster than inflation. This pattern has persisted throughout the 1980s. This has important implications for drug profit margins, as discussed below.

Another significant change during the 1980s relates to sales of U.S. introductions in foreign markets. Throughout the previous decade, an upward trend was observable in the ratio of foreign to domestic sales for U.S. drug firms. However, during the $1980 \mathrm{~s}$, foreign sales have not increased relative to U.S. drug sales. This reflects the oscillating movements in exchange rates as well as the moderating growth rates of pharmaceuticals in foreign markets.

In sum, there have been major structural changes in recent years influencing both the inputs and outputs from pharmaceutical $R \& D$. Hence studies of the returns to R\&D which simply extrapolate the trends of the 1960s and 1970s to future periods are likely to have significant limitations. ${ }^{6}$ A re-examination of the returns to R\&D utilizing more recent industry experiences and data would therefore appear appropriate.

\section{Data Samples and Methodology}

\section{A. Overview}

As discussed, the first objective is to measure the historical performance of New Chemical Entities (NCEs) introduced during the 1970s. The basic sample is 100 NCEs approved by the FDA and introduced into the United States between 1970 and $1979 .{ }^{7}$ For each NCE, annual cash flows are estimated over the compound's projected product life. A key question analyzed is whether the present value of cash flows from the average NCE covers average R\&D investment costs, including the opportunity cost of capital. This

\footnotetext{
${ }^{5}$ The Drug Price Competition and Patent Restoration Act allows easier approval of generic products by the FDA and also results in longer effective patent lifetimes for new drug introductions. However, the primary short-run effect of the Act is to facilitate generic competition for drugs now coming off patents. A preliminary analysis of these developments and the economic impacts of the Act is presented in Grabowski and Vernon (1986).

${ }^{6}$ In this regard, Joglekar and Patterson (1986) assume in their base case analysis that the ratio of worldwide sales to U.S. sales would increase steadily and that drug prices would lag overall inflation during the rest of the century, based on an extrapolation of trends observed in the 1960s and 1970s. If one modifies these assumptions to take account of the 1980s experience in pharmaceuticals, rates of returns are influenced in both a positive and negative manner.

${ }^{7}$ Our sample excludes new drugs in the cancer area because they are typically developed jointly with the National Institutes of Health. Similarly drugs discovered and developed by nonprofit institutions and universities are excluded because the $R \& D$ costs of these compounds would not be representative of drugs emanating from the pharmaceutical industry.
} 
analysis is performed on a real after-tax basis. Both cash flows and R\&D expenditures are expressed in constant 1986 after-tax dollars, utilizing a tax rate appropriate to the pharmaceutical industry.

The analysis is performed from the perspective of a long-run capital investment decision. Hence, cash flows are compared to fully allocated R\&D investment expenditures. The latter include discovery costs common to all NCEs and the costs associated with R\&D failures. It is, of course, rational for firms to continue to make incremental investments as long as cash inflows are expected to cover all future cash outflows on a net present value basis. Over the long run, however, a firm's total portfolio of new drug introductions must cover all investment costs, including "dry holes" and opportunity costs, if R\&D is to remain a viable enterprise. In this regard, it is therefore instructive to ask whether the full portfolio of drugs emanating from the pharmaceutical industry over a period of several years covers the industry's opportunity cost of capital. This is a principal issue to be considered in the first half of the paper.

\section{B. Opportunity Cost of Capital}

The cost of capital for pharmaceuticals in this study is based on an analysis of the capital asset pricing model (CAPM) estimated at various points in time between mid$70 \mathrm{~s}$ and mid $80 \mathrm{~s}^{8}$ An analysis of investment riskiness was first undertaken for a representative portfolio of pharmaceutical firms. This indicated that pharmaceutical firms had comparable riskiness to the market over this period (i.e., betas approximately equal to one). Long-term estimates on the risk free rates and the market equity risk premia were then obtained using the analysis of Ibbotson (1987). Using these inputs to the CAPM, the estimated cost of equity capital for pharmaceuticals exhibited a central tendency around 9 percent for the time period studied. ${ }^{9}$ This value is utilized therefore to capitalize $\mathrm{R} \& \mathrm{D}$ costs and all cash flows in the present analysis. ${ }^{10}$

\section{C. $R \& D$ Costs}

The most comprehensive analyses of $\mathrm{R} \& \mathrm{D}$ expenditures in pharmaceuticals was performed by Ron Hansen $(1979,1980)$. He utilized cost data from a significant sample of

\footnotetext{
${ }^{8}$ Since the capital structure of pharmaceuticals is overwhelmingly equity financed (in excess of 90 percent), the cost of equity capital provides a good proxy for the overall cost of capital. This issue has been examined in Statman (1983). Joglekar and Patterson (1986) compare R\&D returns in pharmaceuticals with the returns on corporate bonds. As the authors recognize, this is a very conservative approach, in that the returns on corporate bonds have been significantly below that for equities over the relevant time period.

${ }^{9}$ The return on long-term government bonds rather than the return on short-term bills was used to compute the risk free rate (and the market equity risk premia) since we are dealing here with long term investment projects. The basic Capital Asset Pricing Model formula is
}

Cost of Equity Capital $=$ Risk Free Rate $+($ Beta $)($ Market Risk Premium $)$.

Setting Beta for pharmaceuticals equal to one and using values published in Ibbotson (1987) to obtain the market equity risk premia and risk free rates (in real terms) yields the following results for 1974 and 1986:

$$
\begin{aligned}
& \text { Real Cost of Equity Capital }(1974)=1.3+(1) 7.5=8.8 \%, \\
& \text { Real Cost of Equity Capital }(1986)=1.6+(1) 7.4=9.0 \% .
\end{aligned}
$$

The values for intervening years also cluster around 9 percent.

${ }^{10}$ An alternate approach to estimating the cost of capital would be to utilize the "hurdle rates" derived from surveys of U.S. industrial firms. These hurdle rates are significantly higher than the cost of capital values estimated from the CAPM, especially for R\&D oriented industries like pharmaceuticals (Gitman and Mecurio 1982, Scherer 1983). Some recent research has attempted to reconcile these different findings by generalizing the CAPM in a number of directions (Bernhein and Shoven 1989). This research, while preliminary in nature, points to cost of capital values that are more in line with revealed U.S. corporate hurdle rates. From this perspective, the 9 percent value utilized in this study may be viewed as a conservative estimate of the equity cost of capital for pharmaceuticals. 
new drug candidates undergoing clinical development in the period 1963 to 1975 . Hansen's work is a useful starting point for estimating R\&D costs for our sample of new drugs. However, his R\&D cost estimates cannot be used directly here without adjustment. This is because his study is centered on a time period which predates our sample period. There are several factors that have caused $R \& D$ costs to increase in real terms over time. These include rising real costs for pharmaceutical R\&D inputs, ${ }^{11}$ a longer R\&D process, ${ }^{12}$ and increasing concentration of $\mathrm{R} \& \mathrm{D}$ on chronic disease problems. ${ }^{13}$ At the same time, there is some indication that success rates in clinical development have improved over time. ${ }^{14}$

In the current study, we utilize two separate approaches to estimate R\&D costs. The first approach uses Hansen's R\&D costs by therapeutic class as a starting point. Annual costs by therapeutic class are then adjusted to take account of the net growth in real $R \& D$ costs resulting from the various factors mentioned above ( $R \& D$ input inflation, longer R\&D times, etc.). The second approach relies on total R\&D expenditures and NCE introductions for the pharmaceutical industry. Specifically this approach employs a variable lag analysis between aggregate $R \& D$ expenditures and introductions to estimate average $R \& D$ costs in the 1970s. The two approaches are described in greater detail in a separately available appendix.

The results of these two approaches yield very similar values for average R\&D costs over the 1970s. In particular they indicate the average R\&D costs for 1970-79 introductions, capitalized at 9 percent and expressed in 1986 dollars is in the neighborhood of 125 million dollars. ${ }^{15}$ By way of comparison, Hansen's original average R\&D cost estimate, capitalized at 9 percent and updated for inflation, would be equal to 100 million dollars in 1986 dollars. The difference between these values provide a measure of the net increase in real R\&D costs during the 1970s. A recent study by Wiggins ( 1987) also finds that $R \& D$ costs have increased significantly in real terms over time. ${ }^{16}$

We also found that there is a considerable variance around our mean R\&D cost estimate. In particular, the year to year fluctuations can be 20 percent above or below the average. Recognizing this, we examine a range around the baseline value in the sensitivity analysis.

${ }^{11}$ An analysis of this issue for several industrial sectors was performed by Mansfield, Romeo and Switzer (1983). Pharmaceuticals was subsumed in the broader chemicals class in their analysis. This latter sector experienced a 122 percent price increase over 1969-1979 as compared to an 88 increase for the GNP price deflator. This type of analysis also has been generalized and extended to more recent time periods by Mansfield (1987).

${ }^{12}$ Mattison, Trimble and Lasagna (1988) show that total R\&D times for self-originated NCEs of U.S. firms have increased from approximately 9 years in 1970 to 14 years by 1981 . This factor by itself results in an approximately 2 percent annual increase in real R\&D costs.

${ }^{13}$ In this regard, data collected annually by the Pharmaceutical Manufacturers Association show that cardiovascular research has accounted for an increasing percentage of total industry $\mathrm{R} \& \mathrm{D}$, while research on antiinfectives, has experienced corresponding declines (PMA Statistical Factbook 1988). The analysis of Hansen (1980) indicates significantly lower R\&D costs for acute indications compared to categories involving chronic diseases.

${ }^{14}$ Mattison, Trimble and Lasagna (1988) provide an analysis of this issue. They find that success rates for drugs in clinical development in the United States are increasing over time, but a major reason for this fact is that more drugs are being pre-screened abroad before entering U.S. clinical testing. Preliminary results from an updated analysis of pharmaceutical R\&D by Hansen et al. (1989) also suggest an improving success rate over time, but at the same time indicate that $R \& D$ costs per new drug introduction are growing significantly faster than inflation. On the basis of these new survey data, our adjustments to Hansen's original R\&D costs for the 1970s would appear on balance to be conservative.

${ }^{15}$ The first approach yielded mean R\&D costs per 1970s introduction between 120 and 132 (pre-tax) million dollars, using alternative assumptions for the net effect of the different factors leading to higher real cost over time. The second approach yielded a mean R\&D cost of 123 million dollars with a substantial year to year variation. For further details, see the appendix which is available on request from the authors.

${ }^{16}$ Wiggins' study is not strictly comparable to ours in that it focuses on a longer time period (1960-1975) and utilizes a somewhat different methodological approach (i.e. a short fixed time lag between aggregate R\&D costs and NCE introductions). However, his findings are qualitatively consistent as indicated above. 
In addition, NCE introductions in the latter half of the 1970s have significantly higher mean R\&D costs than those introduced in the first half of the 1970s. This is relevant when we examine particular time cohorts in our analysis of R\&D performance.

\section{Domestic Sales Revenues and Product Life Cycles}

We next turn to the issue of estimating cash flows for our sample of NCE introductions. The first step in this estimation process was to assemble data on the U.S. sales for each new product introduction. For each of the NCEs first marketed between 1970 to 1979 , annual drugstore and hospital sales through 1986 were obtained from audit data sources. From this data base, there were 17 years of sales data for the 1970 NCE introductions, 16 years for the 1971 cohort, 15 years for $1972 \mathrm{NCE}$ introductions and so on down to 8 years of sales data available for the 1979 cohort.

The next task is to extrapolate future sales over the market life of each product. On the basis of prior studies and the sales patterns observed in this sample, 25 years was chosen as the market life for the present sample of drugs. ${ }^{17}$ In order to project sales for the full product life of 25 years, a standard life cycle pattern for drugs sales was utilized (Thomas 1981, Stauffer 1975). Our procedures are illustrated in Figures 1-A and 1-B where the sales data and projections from two representative drugs, selected from the top few deciles of sample compounds, are presented.

The compound in Figure 1-A is one in which 17 years of actual sales are available from audit sources. This compound is beyond its point of peak sales and already has experienced patent expiration. Sales in the first year after patent expiration have begun to decline sharply due to generic competition. In projecting sales in this post-patent period, we assume that drug products in our sample will experience a cumulative loss of 60 percent in sales to generic competitors within a five-year period. This is in line with recent empirical analyses (Grabowski and Vernon 1989, Drexel et al. 1988).

By contrast, the drug compound in Figure 1-B is a more recent introduction. It has many fewer years of actual sales data available ( 9 years). This drug is in the peak sales portion of its product life cycle. Using our representative life cycle curve, this product is projected to have relatively stable sales until year 12 . This is the year when its patent expires and generic entry occurs. A significant decline in sales is projected after that point due to both generic competition and product obsolescence.

Our procedures produce a representative life cycle sales pattern for each new drug introduction that is related to its specific patent date and other economic factors. The amount of error introduced into our present value analysis from the extropolated sales values should be minimal. This is because we have actual sales data for most compounds through their period of peak sales. Furthermore, the later segments of the product life cycle are not only subject to intensive generic competition, but are also heavily discounted in present value terms.

Figure 2 shows the life cycle sales estimates for the mean, median and the top few deciles of our sample. This figure illustrates the highly skewed distribution of sales which exists for new product introductions in pharmaceuticals. In particular, the peak sales of the top decile are several times that of the next ranked decile of drugs. In addition the mean values are much higher than the median. This high degree of skewness has important implications for the returns to pharmaceutical R\&D.

\section{E. Worldwide Sales Revenues}

To obtain estimates of worldwide dollar sales, we utilize a foreign sales "multiplier." In an earlier paper, we examined domestic and worldwide sales for a representative

\footnotetext{
${ }^{17}$ As noted (see fn. 6), there are indications that product life cycles have been shortening. As a consequence, many of the introductions made toward the end of the 1970s may experience shorter market lifetimes than 25 years. This issue is considered in the sensitivity analysis.
} 


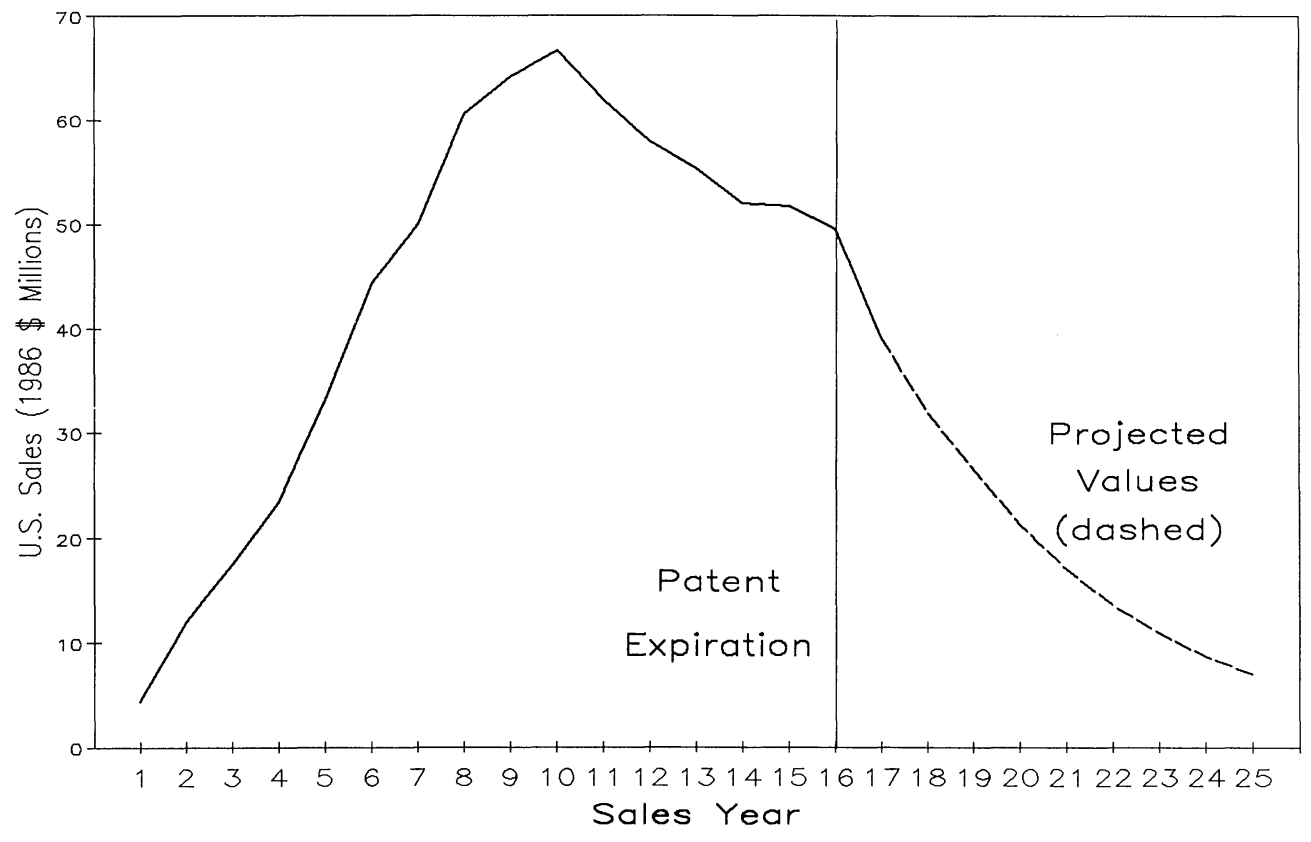

FIGURE 1-A. Historical/Projected Sales Values-Product A.

sample of U.S. NCE introductions during the mid 1970s (Grabowski and Vernon 1982). The relevant multiplier for global to U.S. sales was found to be 1.75 for this period. There is also evidence that this multiplier was increasing throughout the 1970s and reached a value of just over 2.00 by the end of the decade (PMA 1988).

The 1980s have witnessed contrasting trends in this multiplier, primarily as a consequence of exchange rate fluctuations. Consistent with the strong appreciation of the

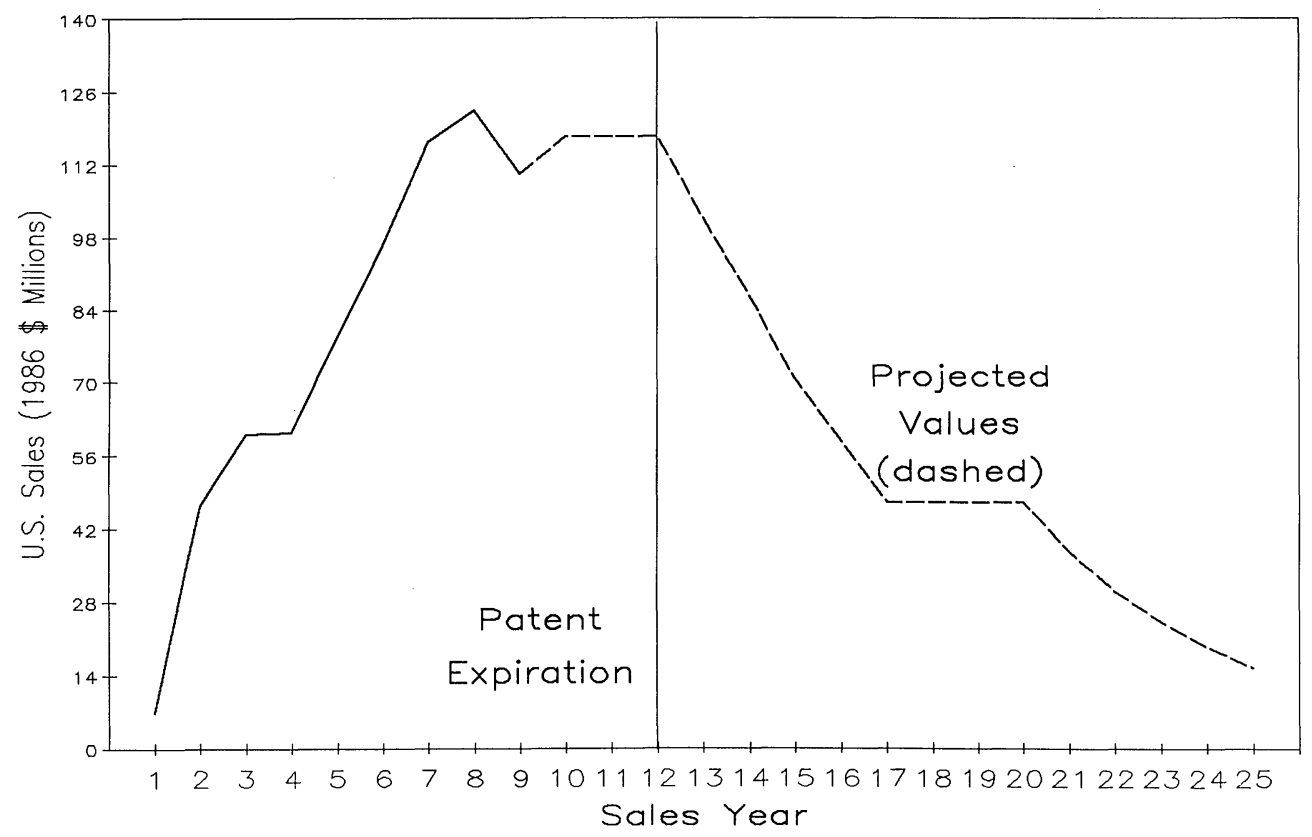

FIGURE 1-B. Historical/Projected Sales Values-Product B. 


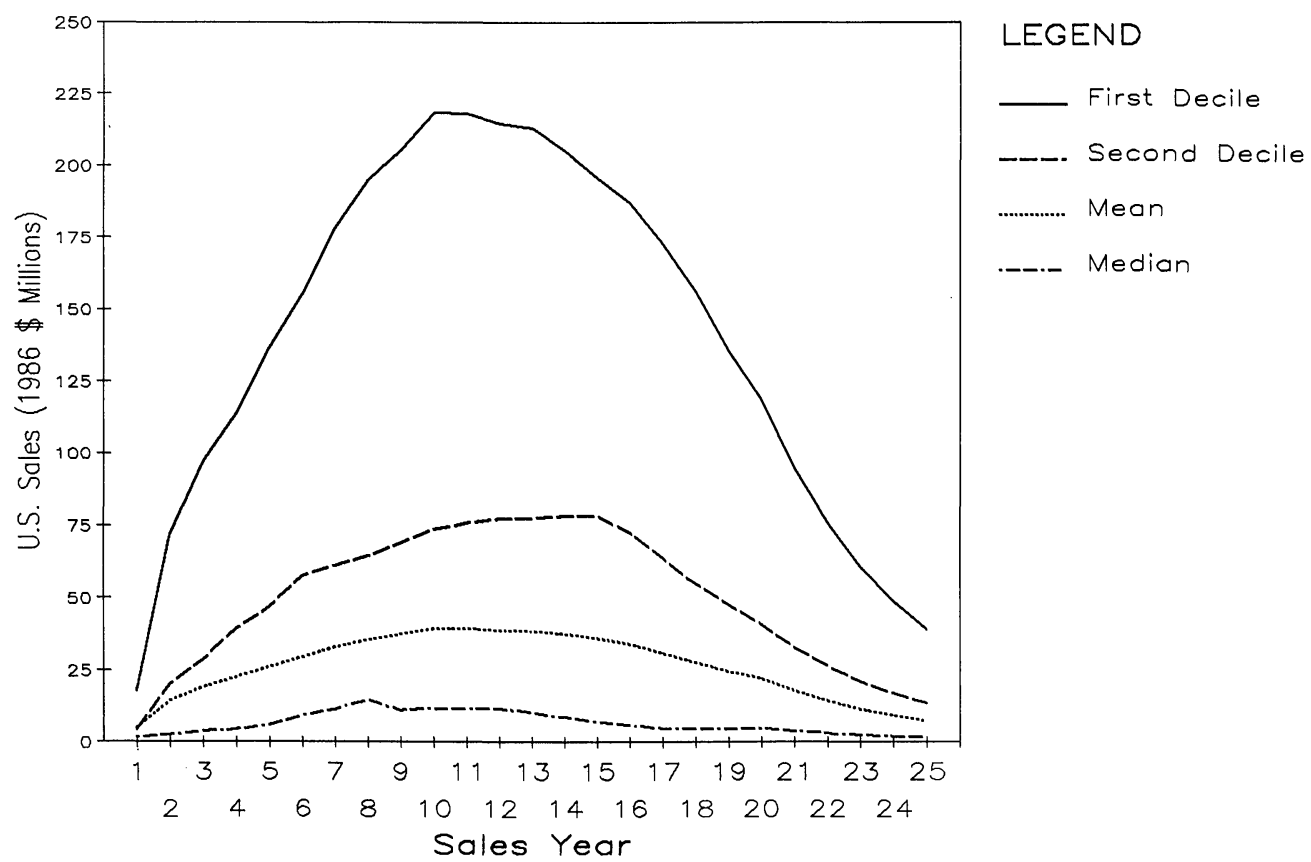

FIGURE 2. Sales profile of 1970-79 Cohort.

dollar in the years prior to 1985 , the ratio of worldwide sales to U.S. declined significantly until the mid-1980s. It has partially recovered in value since that point. This pattern is borne out by balance sheet data on U.S. and foreign sales of multinational pharmaceutical firms as well as other data sources.

These different data sources indicate that the ratio of worldwide to U.S. sales has fluctuated between 1.75 to just over 2.0 for the decade of the $1970 \mathrm{~s}$ and $1980 \mathrm{~s}$. This would also appear to be a relevant range for the immediate future using U.S. Treasury Department's exchange rate projections. Accordingly, a representative value of 1.9 is utilized for the worldwide sales multiplier in our baseline analysis. The broader range of observed values is examined in the sensitivity analysis.

\section{F. Pricing Trends and Pre-tax Contribution Margins}

To obtain cash flows from sales, sales are multiplied by the pre-tax "contribution" margin (i.e., pre-tax profits plus R\&D costs as a percent of sales). Past studies of the returns to R\&D have used contribution margins between 25 and 45 percent. The contribution margin also has been typically assumed to be constant over time, despite the fact that change in real drug prices will cause margins to fluctuate in a corresponding fashion.

In this study, margins are derived using income statement data from the pharmaceutical business divisions of twelve major health oriented firms. Using this information (and data on R\&D to sales ratios from industry trade sources), we estimated average drug industry contribution margins over the period $1973-1986 .{ }^{18}$ These values are plotted in

\footnotetext{
${ }^{18}$ Ideally, one would have data on margins on new product introductions rather than data for all pharmaceutical products. It is not clear what biases this introduces into the analysis. Reekie (1979) has found that products with significant therapeutic advantages over existing products will command a price premium. At the same time, he found many products are launched at discounts compared to market leaders. In addition, recent work suggests that older drugs experiencing generic competition do not typically lower prices to match those of their cheaper rivals. Rather, they usually increase prices while their unit sales erode (Grabowski and Vernon 1989). Since these post-patent drug products have much lower distribution and administrative costs, they could have higher margins than a representative grouping of newer products.
} 


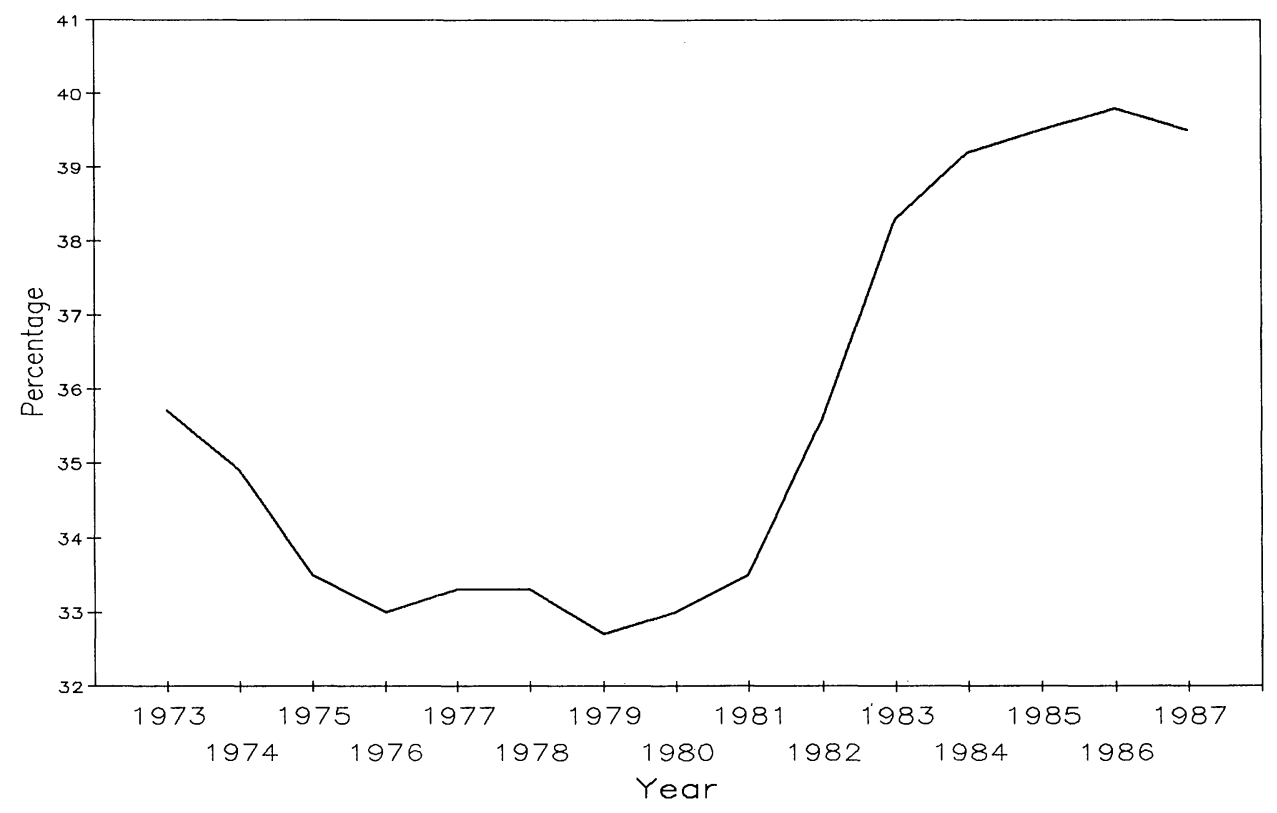

FIGURE 3. Margins Used as Inputs in the Baseline Case: 1973-1987.

Figure 3. The observed time pattern on margins corresponds directly with the behavior of domestic prices. Prices lagged inflation until the late 1970s. They began increasing faster than general inflation in 1981, which is also the year when profit margins in Figure 3 begin significantly increasing. We tested the hypothesis that the changes in margins over this time period could be primarily explained by domestic prices, using a statistical regression analysis. The analysis provided strong formal support for this hypothesis. ${ }^{19}$

We use the pre-tax margins shown in Figure 3 to estimate the pre-tax cash flows generated by each product's sales in a given year. Hence, in contrast to past work, our analysis utilizes time dependent margins. A product launched in the early 1970s would thus have moderately declining margins on its sales until the late 1970s, at which point its margins would begin significantly increasing as one comes forward in time to 1987. In this way, our analysis incorporates the changes in real prices that have occurred in pharmaceuticals since the early 1970s.

For future years, we assume in the baseline case that margins will remain fixed at the 40 percent level observed over recent years. ${ }^{20}$ One might alternatively postulate that margins in the 1990s will decline as a result of increased cost containment pressures in the U.S. and abroad. A number of financial industry reports have projected this kind of

\footnotetext{
${ }^{19}$ In particular, a "backcasting" model for predicting margins was first constructed. Margins were estimated based on the assumption that U.S. drug output prices change in accordance with the pharmaceutical producer price index, while U.S. product input costs increase with the GNP price deflator. For foreign markets, prices were assumed to move proportionally with costs. Using these assumptions, along with an assumed value of 40 percent for margins in 1985 , values were estimated back to 1973 . The estimates produced by this procedure were highly correlated with the margins based on industry accounting data shown in Figure 3 . The correlation coefficient, $R$, between the two series is 0.93 . This implies that domestic real price increases explain 87 percent of the variation in contribution margins using this model.

${ }^{20}$ The plateauing of profit margins in the 1985 to 1987 period at 40 percent is perhaps surprising, given the fact that domestic prices are still increasing faster than economy wide prices. However, in recent years, prices in a number of key foreign markets, such as Japan, have been significantly restrained (OECD, 1987). Foreign sales account for nearly half of the total sales of U.S. firms and hence have nearly equal weight in the determination of margins. The last few years have been characterized by a situation of rising margins domestically and falling ones internationally, apparently leading to relatively stable profit margins for the U.S. pharmaceutical industry.
} 
scenario (Mabon, Nugent and Co. 1987). Alternative scenarios, with both declining and increasing trends for future margins, are considered as part of the sensitivity analysis.

\section{G. Tax Rates}

An analysis of historical data since 1970 indicates that the average effective tax rate for most drug firms has been in the range of 30 to 45 percent. This is below the statutory rate and reflects various credits available in federal laws which lower average effective rates. $^{21}$ The recently enacted Federal tax reform reduces the federal statutory rate for corporations in future periods, but also curtails the ability of firms to utilize particular credits to lower effective tax rates. It is not clear at this point whether effective tax rates will change significantly.

Based on our empirical analysis, a 35 percent tax rate is utilized as a representative baseline tax rate for the pharmaceutical industry for the period of study. This rate was also employed by Joglekar and Patterson (1986) in their recent study. Since both R\&D inputs and cash flow revenues are affected in a roughly proportional manner by the tax rate, our present value analysis should not be highly sensitive to the tax rate parameter utilized. This issue is examined in the sensitivity analysis.

\section{H. Outlays for Product Launch, Fixed Capital and Working Capital}

Pharmaceutical products typically experience heavy promotional expenditures in the first few years of product launch. In the current analysis we assume promotional expenditures equal to sales in year one, declining to 50 percent and then 25 percent of sales respectively in year two and three after product launch. This is based on a separate analysis of drug promotion expenditures for new products using audit data from IMS. These upfront promotional expenditures result in realized pre-tax margins below the assumed steady state values in the first few years of market life, in accordance with general industry experience.

In our analysis, total plant and equipment expenditures are assumed to be equal to 50 percent of tenth year sales for each new product introduction. ${ }^{22}$ This ratio was based on balance sheet data of firms with a high degree of specialization in pharmaceuticals. For working capital, it is assumed that accounts receivable represent 1.3 months of annual sales and inventories are 5 months of sales (valued at the product's manufacturing cost). All working capital is recovered in the final year of product life.

After-tax cash flows are also affected by differences in book and tax depreciation methods. Book depreciation is based on a straight line accounting method, while tax depreciation is based on an accelerated schedule in accordance with the U.S. tax code. The more rapid depreciation for tax purposes results in positive cash flow in earlier years in the form of deferred taxes, which then reverses in later years.

\section{Results}

\section{A. Average Investment Returns}

Using the above data and assumptions, we first examine the performance of the mean NCE introduction during the 1970s. The results are presented in Table 1. A major finding is that the present value of cash flows and $R \& D$ investment are approximately the same

\footnotetext{
${ }^{21}$ Both the investment tax credit (repealed by the 1986 Tax Reform Act) and research and development tax credit (reduced by this Act) are reflected directly in the average effective tax rate of the pharmaceutical industry. A more refined analysis would investigate the effects of these factors separately rather than combining them in a net effective tax parameter. However, as shown below, the results are not highly sensitive to tax rates.

${ }^{22}$ Approximately two-thirds of the required capital expenditures are allocated in the two years prior to product launch. The remaining outlays are allocated between year two and ten of product life and are used for maintenance and replacement capital.
} 
TABLE 1

Investment Performance of the Average New Product Introduction During the 1970s

\begin{tabular}{llccc}
\hline Cohort $^{1}$ & \multicolumn{1}{c}{ Case } & $\begin{array}{c}\text { Present Value } \\
\text { Cash Flows }\end{array}$ & $\begin{array}{c}\text { Present Value } \\
\text { R \& D Costs }\end{array}$ & $\begin{array}{r}\text { Year When NPV } \\
\text { Becomes Positive }\end{array}$ \\
\hline $1970-79$ & Baseline $^{3}$ & 83.5 & 81 & 23 \\
$1970-74$ & Baseline & 49.0 & 72 & Never \\
$1975-79$ & Baseline & 111.7 & 92 & 17 \\
\hline $1970-79$ & Constant Margins & 81 & Never \\
$1970-74$ & Constant Margins & 69.8 & 72 & Never \\
$1975-79$ & Constant Margins & 43.7 & 92 & Never \\
\hline
\end{tabular}

${ }^{1}$ There are 100 new drug introductions in the full sample (1970-79); There are 43 introductions in the 197074 subsample and 57 introductions in the 1975-79 subsample.

${ }^{2}$ Cash Flows and R \& D Costs are after-tax and are expressed in millions of 1986 dollars. They are discounted at $9 \%$ from the date of marketing.

${ }^{3}$ Baseline parameters assume a 25 year market life, a tax rate of 35 percent, a worldwide sales multiplier of 1.9 , and variable pre-tax tax margins by calendar year (see text).

${ }^{4}$ Margins are assumed constant at 33 percent value after 1979 (i.e. no real price increases in pharmaceuticals). All other parameters are assumed to be the same as in the baseline case.

over the 1970 to 1979 sample period. The first entry of Table 1 shows the present value of after-tax cash flows (exclusive of $R \& D$ ) for the mean compound is equal to 83.5 million dollars. The second column shows that the average after-tax R\&D investment for 1970s introductions, also capitalized at 9 percent, is 81 million dollars. This approximate equality between the present value of cash flows and R\&D costs implies that the average new product introduction in the 1970s earned a return in the neighborhood of 9 percent, in line with the industry's cost of capital.

The results in Table 1 also indicate that the average investment for the 1970-79 period takes 23 years from the date of marketing introduction to achieve a positive net discounted present value. This is illustrated in Figure 4. The cumulative present value curve for the mean compound achieves equality with $R \& D$ investment ( 81 million dollars) in year 23 of market life. This is close to the assumed product life of 25 years. If new products in the future are characterized by shorter effective lifetimes (e.g., 20 years), then, ceteris paribus, the average NCE would not produce a discounted payback over its lifetime. This issue is considered further below in the sensitivity analysis.

\section{B. Performance in the 1970-74 Period Compared to 1975-79}

Table 1 also provides present values and discounted payback periods for the two subperiods 1970 to 1974 and 1975 to 1979 . This shows that the performance of the average NCE in the first half of the 1970s was very different from the second half. In particular, the average NCE in the 1970-74 period has an estimated present value significantly below its R\&D investment and experiences a loss of over 20 million dollars. At the same time, the average NCE introduction in the second half of the 1970s has an estimated present value which significantly exceeds its $R \& D$ investment and achieves a positive discounted payback by the 17 th year after introduction. ${ }^{23}$

While the observed positive change in performance between the first and second half of the 1970s may be the result of normal statistical fluctuations, it is also consistent with

\footnotetext{
${ }^{23} \mathrm{We}$ also examined the internal rate of return for these two subperiods. This analysis is subject to the qualification that there is uncertainty about the time pattern of $R \& D$ costs applicable to these sample periods. However, if one essentially utilizes a time pattern for R\&D identical to Hansen's ( with proprotional adjustments in annual costs), the internal rate of return is equal to 7.1 percent for the $1970-74$ period, while it is 10 percent for the 1975-79 period.
} 


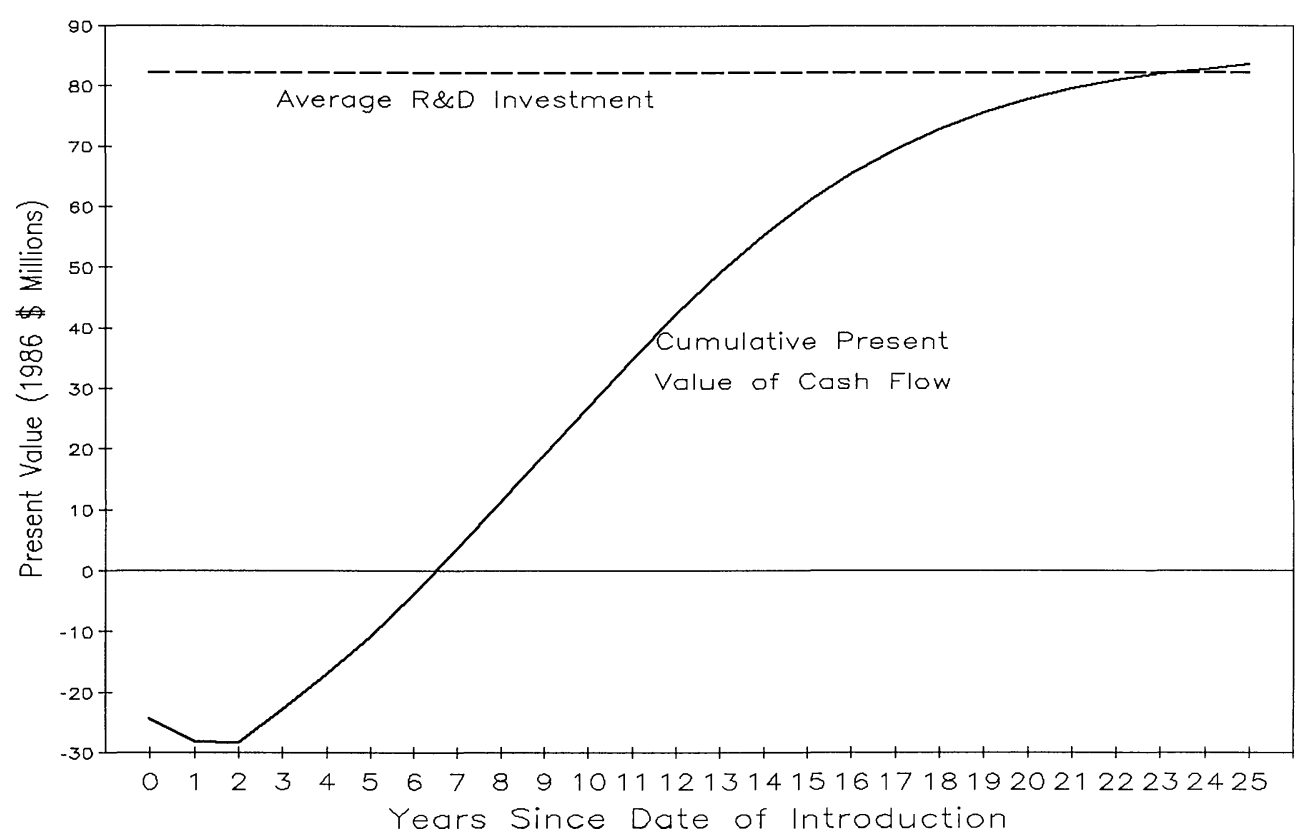

Figure 4. Present Value of Cash Flow vs. R\&D Investment for the Mean New Product Introduction over 1970-79 Period.

the observed behavior of the pharmaceutical industry's R\&D expenditures. Over the period 1977 to 1987 , real R\&D expenditures in pharmaceuticals have more than doubled. This is a much faster rate of growth than in the previous decade and also than for other developed countries (Grabowski 1989). The upward shift in the growth of U.S. R\&D expenditures dovetails with our finding of a positive shift in returns for the average new product introduction in the latter part of the 1970s.

\section{The Distribution of NCE Revenues}

In Figure 5, the present value distribution of returns by deciles for NCEs introduced during the 1970 to 1979 period is presented. As this figure illustrates, this is a highly skewed distribution. The top decile has an estimated present value of 457 million dollars. This is several times the average present value of $R \& D$ costs ( 81 million dollars). At the same time, only the top few deciles have present values in excess of average R\&D costs. ${ }^{24}$

The skewed distribution of returns presented in Figure 5 point up the importance of the top decile drugs to drug industry performance. This can be also illustrated by analyzing how average present values change when the top decile of compounds is excluded. This results in a decrease in the present value of the mean compound by approximately 50 percent. Indeed, if we exclude only the single largest selling compound introduced during the 1970s, Tagamet, the mean present value for the remaining 99 compounds declines from the baseline value in Table 1 by 14 percent. These computations illustrate the

${ }^{24} \mathrm{We}$ investigated the issue of whether R\&D costs were positively related to a compound's decile class. We found there was a slight positive (but statistically insignificant) relationship between a compound's decile class and its R\&D costs. However, our analysis was able to formally analyze only two components of the variance in R\&D costs-those associated with therapeutic class and year of introduction. It is possible that other factors contribute to a positive relationship between $R \& D$ costs and sales. This is an important issue for further research. However, it seems clear from the analysis that sales are much more skewed than R\&D costs. 


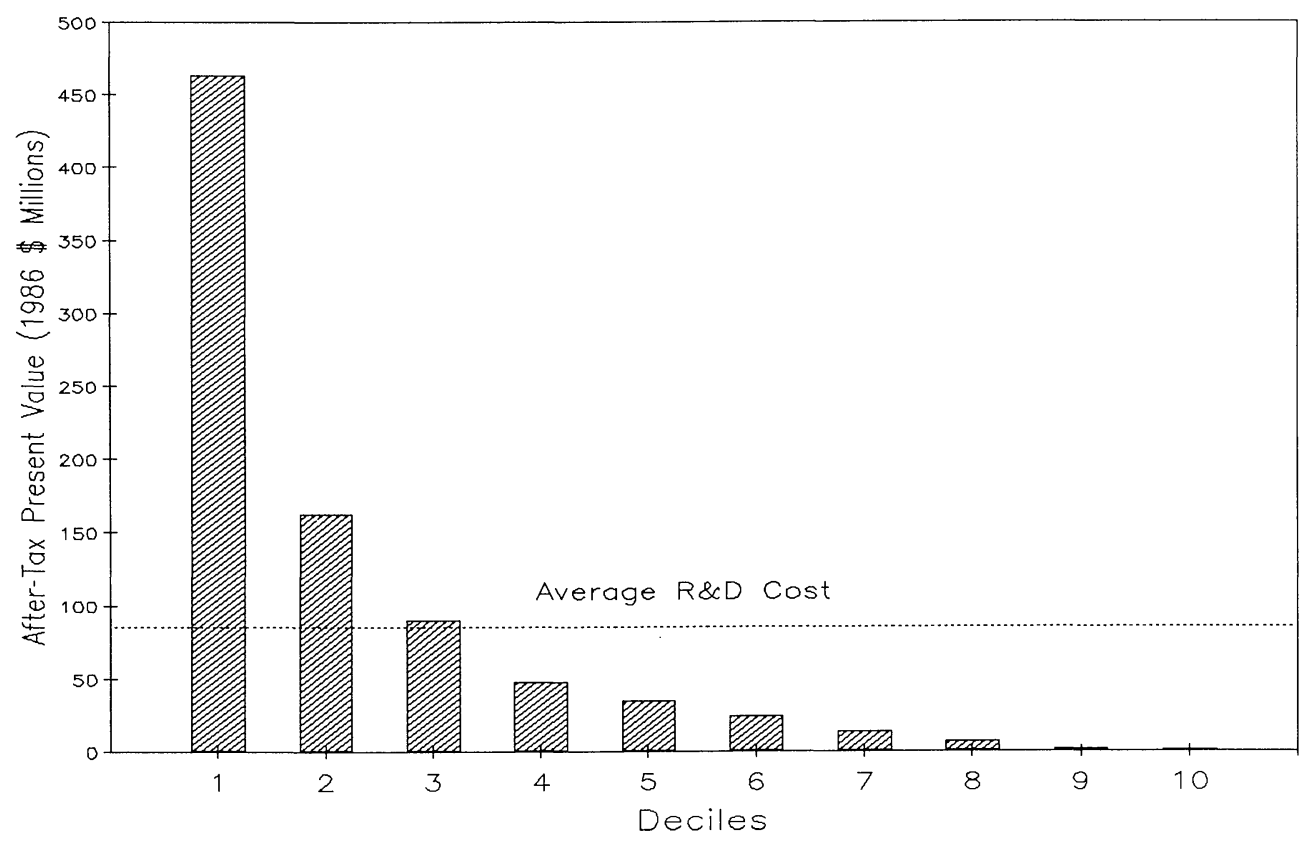

FIGURE 5. Present Values by Decile for the 1970-79 Cohort.

central importance of the top decile compounds to the economic viability of the pharmaceutical industry. ${ }^{25}$

The distribution of present values exhibited in Figure 5 indicate that the majority of new drug introductions in our sample have present values below average R\&D costs. While many of these lower decile products will be contributors to firm profits (in the sense that incremental expected cash flows exceed incremental development and capital investment cost), a firm's fully allocated $R \& D$ costs must also be covered over the long run. In this regard, the results indicate that a firm must have an occasional "blockbuster" compound from the top deciles of the sales distribution, if it is to cover the large fixed costs which characterizes the drug development process.

\section{The Effect of Changing Prices on Present Values}

In this section, our analytical framework is utilized to examine how present values have been affected by the real pharmaceutical price increases that have occurred since 1980. To accomplish this objective, present values are calculated under the hypothetical assumption that contribution margins would have remained constant at their minimum value of the late 1970s. In our analysis, this is tantamount to the assumption that drug prices since 1980 rose only at the rate of inflation (i.e., no real price increases), rather than experiencing net price increases over this period. ${ }^{26}$

The results are reported in the lower half of Table 1. They clearly demonstrate that there is a rather dramatic effect on the computed present values. For the 1970 to 1979 sample, there is a decline of 13.7 million dollars or a 16 percentage point decline from

\footnotetext{
${ }^{25}$ It is also important to note in this regard that eight of the ten drugs which make up the top decile during the 1970s come from the 1975 to 1979 sub-period. Hence, a large factor in the observed upward shift in the economic performance of NCE introductions was the increased number of "blockbuster" products introduced in the latter part of the 1970 s.

${ }^{26}$ In this regard, real price increases were found to explain over 87 percent of the variance in pre-tax margins over the period 1973 to 1985 . See the discussion of this point in footnote 19.
} 
the baseline value. The impact is even larger for the 1975-79 cohort where the percentage decline is over 18 percent.

These changes are significant in light of the fact that the average compound's present value under the constant margin scenario is considerably less than average R\&D investment cost. The analysis therefore indicates that without the real price increases which have occurred since 1980, and holding all other factors the same, the drug industry would not have recovered total allocated costs from their portfolio of 1970 s drug introductions. The rapid rate of growth in industry $R \& D$ expenditures, that has occurred since the late 1970 s, undoubtedly would also have been adversely affected if real prices had remained constant.

\section{Sensitivity of Results to Changes in Various Assumptions}

The analysis of our basic case, presented in Table 1, necessarily embodies a number of assumptions about various parameters and future economic conditions. In this section we examine the consequences of alternative assumptions concerning these parameters.

\section{A. Pre-tax Margins in Future Years}

An alternative scenario to our baseline assumption of stable margins for future periods is declining margins in the 1990s. As discussed above, the case for declining margins over time stems from the likelihood of growing cost containment pressures here and abroad. ${ }^{27}$ Under this case, margins are projected to decline, beginning in 1990, from 40 percent to a steady state value of 36 percent. The latter value is representative of the mean experience for our sample of observed values (Figure 3 ).

The opposite scenario, increasing contribution margins over future periods, is also examined. This could occur if U.S. drug prices in the 1990s were to outpace inflation by an amount sufficiently large enough to dominate the effect of declining real prices abroad. We view this as very unlikely for the reasons cited. Nevertheless, the case of increasing margins is considered in order to see how sensitive the results are to this scenario. Specifically, for this case, it is assumed that contribution margins will steadily rise through the early 1990 s, until they reach a steady state value of 44 percent.

The results for these alternative scenarios are presented in the first two rows of Table 2. We focus on the 1970 to 1979 cohort in these sensitivity analyses. There is not a large impact on the estimated present values for either the increasing or declining margin cases. The new values are within a few percent of previous estimates. This is perhaps surprising, but it reflects the fact that the changes in assumptions about future contribution margins affect only the later years of the life cycle for our sample, and these years are also heavily discounted in economic terms. There would be much greater effects, of course, for new product introductions just beginning their market life at the present time.

\section{B. Greater Generic Competition and Shorter Product Life}

Our basic case embodies assumptions on sales erosion of the pioneer brands to generic competitors that are consistent with current experience. However, there appears to be a strong dynamic trend toward intensifying generic competition. The next decade is likely to witness significantly greater market penetration of generic drugs, consistent with the evolution of cost containment programs in both the public and private sectors. There is currently a strong movement toward increased generic drug usage by HMOs and other managed health care institutions.

In order to test the sensitivity of our results to the prospects of increased generic competition, a scenario was examined in which pioneer sales erode faster over time and

\footnotetext{
${ }^{27}$ Drug prices in recent years have lagged inflation for established drug therapies in all major markets outside the United States. These same cost containment pressures are likely to be increasingly felt in the U.S. market in coming periods.
} 
TABLE 2

Sensitivity of Findings to Changes in Assumptions 1970-79 Cohort

\begin{tabular}{|c|c|c|c|}
\hline Case-Baseline Assumptions Except: & $\begin{array}{l}\text { Present Value }^{1} \\
\text { Cash Flows } \\
\text { (\% Change) }\end{array}$ & $\begin{array}{c}\text { Present Value }{ }^{1} \\
\text { R \& D Costs } \\
\text { (\% Change) }\end{array}$ & $\begin{array}{l}\text { Year When NPV } \\
\text { Becomes Positive }\end{array}$ \\
\hline 1) Declining Margins ${ }^{2}$ in $1990 \mathrm{~s}$ & $\begin{array}{c}81.7 \\
(-2.2)\end{array}$ & $\begin{array}{l}81 \\
(-)\end{array}$ & 25 \\
\hline 2) Increasing Margins ${ }^{3}$ in $1990 \mathrm{~s}$ & $\begin{array}{l}85.3 \\
(2.4)\end{array}$ & $\begin{array}{l}81 \\
(-)\end{array}$ & 22 \\
\hline $\begin{array}{l}\text { 3) Increasing Generic Use \& } \\
\text { Shorter Life }\end{array}$ & $\begin{array}{c}75.8 \\
(-9.2)\end{array}$ & $\begin{array}{l}81 \\
(-)\end{array}$ & Never \\
\hline 4) Case (1) and (3) combined & $\begin{array}{c}74.6 \\
(-10.7)\end{array}$ & $\begin{array}{l}81 \\
(-)\end{array}$ & Never \\
\hline $\begin{array}{l}\text { 5) R \& D Investment Increased } \\
\text { by } 20 \%\end{array}$ & $\begin{array}{l}83.5 \\
(-)\end{array}$ & $\begin{array}{l}98 \\
(20)\end{array}$ & Never \\
\hline $\begin{array}{l}\text { 6) } R \& \text { D Investment Decreased } \\
\text { by } 20 \%\end{array}$ & $\begin{array}{l}83.5 \\
(-)\end{array}$ & $\begin{array}{c}65 \\
(-20)\end{array}$ & 16 \\
\hline 7) 1.75 Worldwide Sales Multiplier & $\begin{array}{c}76.9 \\
(-7.9)\end{array}$ & $\begin{array}{l}81 \\
(-)\end{array}$ & Never \\
\hline 8) 2.05 Worldwide Sales Multiplier & $\begin{array}{l}90.1 \\
(7.9)\end{array}$ & $\begin{array}{l}81 \\
(-)\end{array}$ & 19 \\
\hline 9) $40 \%$ Tax Rate & $\begin{array}{c}75.7 \\
(-9.3)\end{array}$ & $\begin{array}{c}75 \\
(-7.7)\end{array}$ & 25 \\
\hline 10) $30 \%$ Tax Rate & $\begin{array}{l}91.3 \\
(9.6)\end{array}$ & $\begin{array}{l}88 \\
(7.7)\end{array}$ & 22 \\
\hline
\end{tabular}

\footnotetext{
${ }^{1}$ Percent changes are computed from the baseline cases values presented in Table 1 (1970-79 cohort).

${ }^{2}$ Declining margin case assumes that margins drop by one percent a year beginning in 1990 until they reach an equilibrium value of 36 percent in 1993 and then remain constant.

${ }^{3}$ Increasing margin case assumes that margins increase by one percent a year beginning in 1990 until they reach an equilibrium value of 44 percent in 1993 and then remain constant.
}

lose 80 percent of the total market to generics within six years after patent expiration. This is in contrast to the base case which assumes an equilibrium share for generics of 60 percent after five years. Under the increased generic competition scenario, we also assume a shortened product life of 20 years, reflecting the lower sales values associated with the back end of the product life cycle curve.

The results are presented in the third row of Table 2. Increased generic competition and shorter product life reduce the present value of returns in the basic cohort by approximately 9 percent. A breakeven also does not occur within the assumed commercial life for the average drug product.

The same cost containment pressures that are likely to increase generic usage will also probably operate to constrain future prices and margins in future periods. Hence it is useful to consider the case of declining margins and increased generic usage in combination. This case is considered in the fourth row of Table 2. The results show that these factors are largely additive in nature. The present value of cash flows in this case are reduced by over 10 percent below the base case and the gap between returns and R\&D costs is further widened. Once again, the impact of these factors is moderated by the fact that they occur relatively late in the product life cycle here and are significantly discounted for 1970s introductions. If cost containment measures affect future introductions earlier in the life cycle, their impact will be substantially increased.

\section{C. $R \& D$ Investment}

The next sensitivity analysis involves $R \& D$ investment expenditures. The baseline utilized a pre-tax average R\&D investment of 125 million dollars for 1970s introductions. This translates into an after tax value of 81 million dollars given the assumed 35 percent 
tax rate. However there is considerable variability around this average value. Our analysis of year to year fluctuations during the 1970s suggest a plus or minus 20 percent bound would be a plausible range for a sensitivity analysis on this parameter.

In Table 2, rows 5 and 6 , results are presented assuming these alternative values for $R \& D$ investment. As one might expect, our findings are quite sensitive to the $R \& D$ investment variable. An increase of 20 percent in the present value of $R \& D$ outlays creates a significant shortfall between the after tax cash flows and R\&D investment. The average introduction fails to achieve breakeven on a discounted payback basis. On the other hand, a decrease of 20 percent from baseline values has the opposite effect. In particular, the average introduction would then earn almost 20 million dollars and achieve breakeven discounted payback in year 16 of market life. This is 7 years sooner than in the baseline case.

These results point up the importance of upfront R\&D investment to economic performance and breakeven lifetimes. Since FDA regulations and review times are one of the primary factors influencing $R \& D$ investment outlays, this also highlights the important effect that regulatory developments can have on the returns to pharmaceutical R\&D. This is also a principal finding of an earlier study on breakeven lifetimes (Grabowski and Vernon 1982). ${ }^{28}$

\section{Foreign Sales Multiplier}

The next sensitivity analysis presented in Table 2 concerns the foreign sales multiplier. Worldwide sales were set in the baseline analysis at 1.9 times domestic sales based on an analysis of individual product as well as balance sheet data. Table 2 shows the consequences of alternatively assuming worldwide sales at 1.75 and 2.05 times U.S. sales. Present values are changed by approximately 8 percent from the baseline case values. Since these values involve the high and low ends of the spectrum, our results do not appear highly sensitive to this parameter.

\section{E. Effective Tax Rate}

The final two rows of Table 2 show the sensitivity of the results to alternative tax rate assumptions. A representative tax rate of 35 percent is utilized in our base case. Table 2 shows the effect of alternatively assuming tax rates of 30 and 40 percent over the full market life of each NCE introduction. The average present value of returns would be decreased by 9.3 percent if a tax rate of 40 percent is employed. At the same time, however, the present value of the mean R\&D investment would decrease by a comparable amount of 7.7 percent, given that $R \& D$ costs are tax deductible. Consequently, breakeven lifetimes change only marginally from the baseline case and overall, our results are little affected by tax rates changes of this magnitude.

\section{F. Overview}

In general, the results in Table 2 show our findings are quite robust to changes of various parameters within a plausible range around the baseline values. ${ }^{29}$ The most sensitive factor is R\&D investment outlays. Given this result, further analyses of pharmaceutical R\&D costs and how these costs have been changing over time would appear to be a high priority for future work. ${ }^{30}$ Another factor to which returns were sensitive was

\footnotetext{
${ }^{28}$ In our earlier paper, we found that one year reduction in upfront regulatory review time will result in three or more years reduction in the breakeven lifetime (Grabowski and Vernon 1982).

${ }^{29}$ In addition to the sensitivity analyses reported in Table 2, we also considered alternative scenarios for other parameters such as the required investment in physical capital for a typical new drug. The findings of the baseline case were robust to plausible variations in this and other factors.

${ }^{30}$ The 125 million dollar R\&D cost figure for this study is based on the mid-1970's, corresponding to our sample of the 1970's introductions. Given the continuing upward trend in real R\&D costs observed here, the mean R\&D cost of a new drug introduction at the present time should be substantially higher than this value. Preliminary results from a new study of R\&D costs by Hansen et al. (1989) suggest this is the case.
} 
the industry's ability to achieve price increases, especially in the first several years after product launch. This is highlighted by our findings on the effect of changes in the product margins in Table 1.

\section{Summary and Conclusions}

A major finding of this study is that new drug product introductions in the 1970s realized returns in line with the 9 percent industry cost of capital. Our finding in this regard represents a departure from prior work which has generally found lower returns to pharmaceutical $\mathrm{R} \& \mathrm{D}$, both in absolute terms and relative to the industry's cost of capital. One explanation for this difference in findings is that our study considers a more recent sample of NCE introductions and utilizes time trends on sales and cost data through the mid 1980s.

Another important finding is that the economic performance of new drugs introduced during the latter half of the 1970s was markedly better than that of the early 1970s introductions. In this regard, eight of the ten drugs in the top decile of sales during the 1970s represented introductions which occurred after 1974. This fact suggests a possible improving situation in terms of technological opportunities in the pharmaceutical industry which become manifest in the latter half of the 1970s. This hypothesis is consistent with the behavior of industry R\&D expenditures. The industry's growth in real R\&D expenditures has been on the order of 10 percent since 1977, more than double the growth rate of the prior decade. Very preliminary research also suggests that the new drugs introduced during the 1980s experienced sales patterns in their early years of market life that are consistent with the strong economic performance of the late 1970s introductions. ${ }^{31}$

In comparison to past work, our study considers the effects of a number of significant economic changes that have occurred in the pharmaceutical industry over the past decade. Specifically, our analysis indicates that higher real drug prices in the 1980s had an especially important effect in allowing firms to cover R\&D investments. A sensitivity analysis performed in the paper indicated that, if no real price increases had occurred, and drug contribution margins correspondingly remained at their minimum values of the late 1970s, the present value of returns would have been reduced by 16 percent for the average 1970s new drug introduction. Under this scenario, and holding other factors constant, the typical new drug introduction would not have been able to cover average R\&D costs.

Our sensitivity analysis also considered the effects of evolving cost containment pressures in the pharmaceutical industry. These pressures are likely to result in a greater degree of generic competition, shorter product lives and lower margins than assumed in our baseline case estimates. If these factors become increasingly significant during the 1990 s, they would have a negative effect on the returns earned by past introductions. This effect would be moderated by the fact that these events would affect only the later years of market life. However, these changes would have a much larger impact on future new drug candidates. A prospective analysis of the effects of evolving policy changes on future introductions is an important task for further study.

\footnotetext{
${ }^{31}$ Average sales for new drug introductions during the 1980 s are generally equal to or higher than those observed at comparable points in the life cycle of 1970 s introductions. At the same time, mean R\&D costs would also be expected to be greater for these 1980s introductions.
}

\section{References}

Baily, MARTin N., "Research and Development Costs and Returns: The U.S. Pharmaceutical Industry," J. Political Economy, (January/February 1972).

Bernheim, R. Douglas And John Shoven, "Comparison of the Cost of Capital in the U.S. and Japan: the Roles of Risk and Taxes," presented to a Conference of the Center for Economic Policy Research, Stanford University, September 1989.

Drexel, Burnham AND LAMBERT, “Drug Industry Review,” New York, December 1988. 
Gitman, Lawrence J. And Vincent A. Mercurio, "Cost of Capital Techniques Used by Major U.S. Firms," Financial Management, (Winter 1982).

Grabowski, Henry, "Medicaid Patients' Access to New Drugs," Health Affairs, (Winter 1988).

- "An Analysis of U.S. International Competitiveness in Pharmaceuticals," Managerial and Decision Economics, (Spring 1989).

- AND JOHN VERNON, "Structural Effects of Regulation on Innovation in the Ethical Drug Industry." In Essays on Industrial Organization in Honor of Joe S. Bain, ed. R. T. Masson and P. Qualls (Cambridge, Mass: Ballinger, 1976).

- AND — - "A Sensitivity Analysis of Expected Profitability of Pharmaceutical R\&D," Managerial and Decision Economics, (March 1982).

- AND — The Regulation of Pharmaceuticals: Balancing the Benefits and Risks, American Enterprise Institute, Washington, D.C., 1983.

AND - , "Longer Patents for Lower Imitation Barriers: The 1986 Drug Act," Amer. Economic Rev., (May 1986).

AND — , "The Effect of Generic Entry on Market Prices in the Pharmaceutical Industry," Duke University, June 1989.

Hansen, Ronald W., "The Pharmaceutical Development Process: Estimates of Current Development Costs and Times and the Effects of Regulatory Changes," in Issues in Pharmaceutical Economics, R. I. Chien (ed.), Lexington Books, Cambridge, MA, 1979.

- "Pharmaceutical Development Cost by Therapeutic Categories," University of Rochester Graduate School of Management Working Paper No. GPB-80-6, March 1980.

- JOSEPh DiMasi, HenRy GRabOWSKI AND LOUIS LASAGNA, "Preliminary Findings on R\&D costs per NCE Taken into Humans between 1970 and 1982," Mimeographed Tables, Center for the Study of Drug Development, 1989.

IBBotson Associates, Stocks, Bonds, Bills and Inflation: 1987 Yearbook, Ibbotson Associates Inc., Chicago, IL, 1987.

Joglek ar, Prafulla And Morton PAterson, “A Closer Look at the Returns and Risks of Pharmaceutical R\&D," J. Health Economics, (1986).

Mabon, Nugent AND Co., "New Gatekeepers and the Slide Toward Price Competition in the Pharmaceutical Industry," New York, June 1987.

MANSFIELD, Edwin, "Price Indexes for R and D Inputs," Management Sci., 33 (January 1987). , ANTHONy Romeo AND LORna SWITZER, "R\&D Price Indexes and Real R\&D Expenditures in the United States," Research Policy, (April 1983).

Mattison, Nancy, A. Gene Trimble and Louis Lasagna, "New Drug Development in the United States, 1963 through 1984," Clinical Pharmacology and Therapeutics, (March 1988).

OECD, "La Santé, Financement et Prestations," Paris, 1987.

PMA, Statistical Fact Book, Pharmaceutical Manufacturers Association, Washington, D.C., 1988.

ReEkIE, W. DunCAN, "Price and Quality Competition in the United States Drug Industry," J. Industrial Economics, (March 1979).

Scherer, F. M., "Inflation, Capital Budgeting and the Long View," Unpublished manuscript, 1983.

SChWARTZMAN, David, "Pharmaceutical R\&D Expenditures and Rates of Return," in Drug Development and Marketing, R. B. Helms (ed.), American Enterprise Institute, Washington, D.C., 1975.

Statman, MeIr, Competition in the Pharmaceutical Industry: The Declining Profitability of Drug Innovation, American Enterprise Institute, Washington, D.C., 1983.

, "The Effect of Patent Expiration on the Market Position of Drugs," in Robert Helms (Ed.), Drugs and Health, American Enterprise Institute, Washington D.C., 1981.

STAuffer, ThOMAS, "Profitability Measures in the Pharmaceutical Industry" in Robert Helms (ed.), Drug Development and Marketing, American Enterprise Institute, Washington, D.C., 1975.

Thomas, Celia, "The Return To Research and Development in the Pharmaceutical Industry," Unpublished Ph.D Dissertation, Duke University, 1981.

THOMAS, LACY GLENN, "Regulation and Firm Size: FDA Impacts on Innovation," Columbia University Graduate School of Business, First Boston Working Paper Series, FB-87-24, September 1987.

U.S. Congress, House, Subcommittee on Health and the Environment of the Committee on Energy and Commerce, Prescription Drug Price Increases, 99th Congress, First Session, July 15, 1985.

U.S. Congress, House, Subcommittee on Health and the Environment of the Committee on Energy and Congress, Medical Devices and Drug Issues, 100th Congress, First Session, April 21, 1987 and May 4, 1987.

Wiggins, Steven, The Cost of Developing a New Drug, Pharmaceutical Manufacturers Association, Washington, D.C., June 1987. 